\title{
ARTICLE
}

\section{Comparison of Atmospheric Dispersion Factor in Complex Terrain}

\author{
HAO Hongwei* , FAN Dan, YAO Rentai, and XU Xiangjun
}

\author{
China Institute for Radiation Protection, P.O.Box 120, Taiyuan, Shanxi 030006, China
}

\begin{abstract}
Calculations of annual and accident atmospheric dispersion factors (ATFs) for nuclear power plant environmental impact assessment are usually based on the safety series of IAEA and regulatory guides of U.S. Nuclear Regulatory Commission. However, as for the sites in complex terrain especially for low wind speed and calm conditions, it is needed to evaluate the validity and conservation of atmospheric dispersion model and parameters. In this paper, the site chosen for the test was the Fuling nuclear power plant site in Chongqing, which was selected primarily on the basis of the available atmospheric data. The annual ATFs were calculated through simulating the 8760 hourly releases of radioactive nuclides using the three dimensional objective diagnostic wind field model and Lagrangian trajectory puff model. The comparison with the ATFs calculated by the usual models shows that the annual ATFs from hourly simulations is about 2.6 3.4 times depending on different nuclide. Therefore, it should be careful to apply the usual models to the site with complex environmental conditions like Fuling site, and also to analyze the conservative application of the models and parameters. Many works for the accident ATFs evaluation should be also developed and examined.
\end{abstract}

KEYWORDS: atmospheric dispersion factors, calm, complex terrains, puff mode, simulate comparison

\section{Introduction}

In accordance with the safety series of IAEA $^{1)}$ and USNRC regular guides ${ }^{2}$, either Gaussian Straight-line mode or Variable Trajectory modes could be used to calculate annual and accident atmospheric dispersion factors for nuclear power plant environmental impact assessment. It is come to light that the constant mean wind direction model can only use meteorological data from a single station to represent diffusion conditions within the region of interest unlike the variable models, in despite of the Gaussian Straight-line modes similar to $\mathrm{XOQDOQ}^{3)}$ and $\mathrm{PAVAN}^{4)}$ mode are being widely used to calculate atmospheric dispersion factors at present, the effects of spatial and temporal variations in airflow in the region of the site with complex topography and climatological features are usually not described well by these constant mean wind direction models.

Many inland sites were being selected or determined for nuclear power plant in China. Maybe different sites have similar dispersion and airflow patterns, but detailed dispersion patterns are usually unique for each site. In order to evaluate the validity and conservation of atmospheric dispersion model and parameters, the meteorological characteristics in these regions and the topography as well as the representativeness of input meteorological data have to be considered for these inland nuclear power plant sites in complex terrain especially for low wind speed and calm meteorological conditions.

So the inland nuclear power plant in Fuling District Chongqing province with more representative topography features and more relatively detailed hourly meteorological data have been chosen to do a experiment, the results for annual atmospheric dispersion factors calculated separately by A Lagrangian mesoscale trajectory puff model and

*Corresponding Author, E-mail:haohongwei001@sina.com

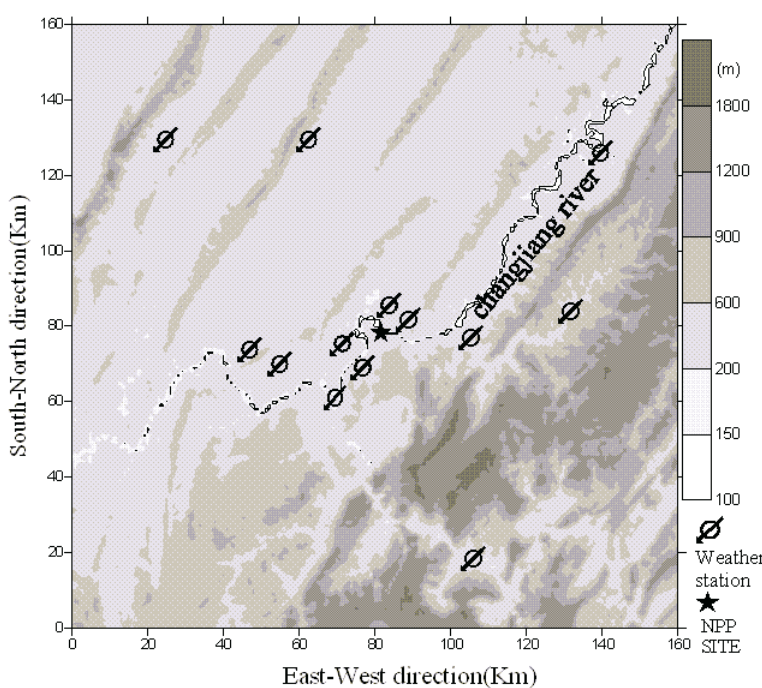

Fig. 1 The Topography and Meteorological Station within a radius of $80 \mathrm{KM}$ of the site center

Gaussian strait-line model were compared and analyzed.

\section{Environmental research}

Fuling nuclear power plant site locates in the east of Sichuan interior basin, the Changjiang River runs across the site from the south to north, then to the south-east. The site is environed by the Changjiang River and lots of rolling hills. Figure 1 illustrates the topography and Meteorological Station within a radius of $80 \mathrm{~km}$ of the site center. Meteorological Station outside of $80 \mathrm{~km}$ of the site center is not marked here.

Besides annual on-site meteorological observation, many experiments and measurements such as atmospheric dispersion, turbulence, wind, and temperature have been carried out over the complex terrain in the region of the site 

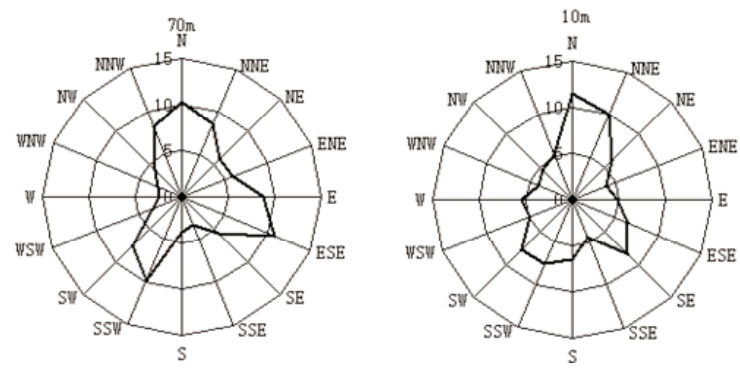

Fig. 2 Annual average wind frequency rose for past two years, 2006 2008. Wind at $70 \mathrm{~m}$ and $10 \mathrm{~m}$ level

Table 1 The annual low wind speed frequency distribution (\%) for two-year period, 2006 2008 from four observation level in the site

\begin{tabular}{ccccc}
\hline Wind speed & $10 \mathrm{~m}$ & $30 \mathrm{~m}$ & $70 \mathrm{~m}$ & $100 \mathrm{~m}$ \\
\hline $0 \sim 0.5 \mathrm{~m} / \mathrm{s}$ & $17.5 \%$ & $21.6 \%$ & $14.3 \%$ & $22.0 \%$ \\
$0.6 \sim 2.0 \mathrm{~m} / \mathrm{s}$ & $76.3 \%$ & $66.1 \%$ & $63.8 \%$ & $51.5 \%$ \\
total & $93.8 \%$ & $87.7 \%$ & $78.1 \%$ & $73.5 \%$ \\
\hline
\end{tabular}

Table 2 The annual atmospheric stability frequency (\%) for two-year period, 2006 2008, in the site, classified by $\Delta \mathrm{T} / \mathrm{U}$

\begin{tabular}{cccccc}
\hline $\mathrm{A}$ & $\mathrm{B}$ & $\mathrm{C}$ & $\mathrm{D}$ & $\mathrm{E}$ & $\mathrm{F}$ \\
\hline $1.9 \%$ & $14.3 \%$ & $15.4 \%$ & $41.7 \%$ & $0.7 \%$ & $26.0 \%$ \\
\hline
\end{tabular}

Table 3 The mixing layer height $(\mathrm{m})$ concurrently with atmospheric stability of the site

\begin{tabular}{cccccc}
\hline A & B & C & D & E & F \\
\hline 480 & 455 & 351 & 272 & 272 & 272 \\
\hline
\end{tabular}

during the past two years. The datum of annual on-site meteorological observation in Table 1 shows the annual frequency distributions for calm less than $0.5 \mathrm{~m} / \mathrm{s}$ and the annual frequency distributions for low wind speed less than $2.0 \mathrm{~m} / \mathrm{s}$ from four observation levels. Table 2 shows the annual atmospheric stability frequency distribution classified by $\Delta \mathrm{T} / \mathrm{U}$ method. Figure 2 shows on-site annual wind rose for two-year period.

A group of local dispersion parameters and mixing layer heights had been obtained by atmospheric dispersion experiment and turbulence measurement and low-altitude radiosonde as well as lost balloon analysis. The wind and temperature datum of about 15 meteorological stations within a radius of $80 \mathrm{Km}$ of the site center were investigated and collected furthermore for the airflow research of the site. Figure 1 shows the location of meteorological stations. Local dispersion parameters are illustrated by Figure 3, and the mixing height concurrently with atmospheric stability is present in Table 3.

The report ${ }^{5)}$ for the study of atmospheric dispersion experiments in the region of Fuling nuclear power plant site can be referenced.

\section{Method}

\section{The Gaussian Straight-line model}

It is important to remember that Gaussian formula is only an approximation. But it is a very convenient hypothesis.
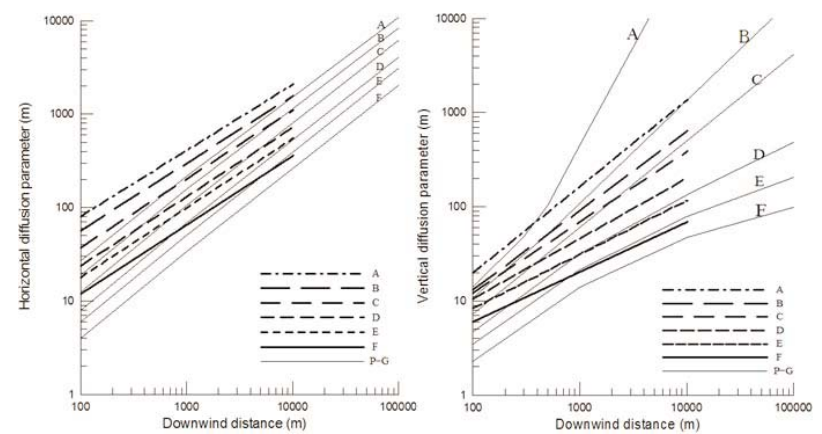

Fig. 3 Atmospheric dispersion parameters in different downwind distance $(\mathrm{m})$, at $70 \mathrm{~m}$ level release, were obtained by the series of 16 local scale atmospheric experiments in the site.

When long-term or annual dispersion factor is calculated, the routine developed by Gaussian Straight-line mode will be distributed evenly across a 22-1/2 degree direction sector. It can calculate concentrations for ground-level and elevated releases. If the release is in a mixed mode, concentrations for both elevated and ground-level releases are calculated, and the resultant concentration value is based on the percentage of time each type of release would occur. The formulas of the model include dispersion, plume arise, building wake effect, decay, depletion due to dry and wet deposition are consistent with the IAEA ${ }^{1)}$ safety Guide No. 50-SG-S3 and USNRC regulatory guide $1.111^{2)}$.

The model is set-up to compute concentrations for 12 downwind distances for each of 16 compass sectors. 12 downwind distances from the release centre include $1 \mathrm{~km}$, $2 \mathrm{~km}, 3 \mathrm{~km}, 5 \mathrm{~km}, 10 \mathrm{~km}, 20 \mathrm{~km}, 30 \mathrm{~km}, 40 \mathrm{~km}, 50 \mathrm{~km}, 60 \mathrm{~km}$, $70 \mathrm{~km}$ and $80 \mathrm{~km}$. The mid point concentration of the centre line of each sector represents each sector concentration.

The hourly wind speed data sets during 2007 to 2008 are divided by six classes, as follows: $0.0 \sim 0.5 \mathrm{~m} / \mathrm{s}, 0.6 \sim 1.9 \mathrm{~m} / \mathrm{s}$, $2.0 \sim 2.9 \mathrm{~m} / \mathrm{s}, 3.0 \sim 3.9 \mathrm{~m} / \mathrm{s}, 4.0 \sim 4.9 \mathrm{~m} / \mathrm{s}, \quad 5.0 \sim 5.9 \mathrm{~m} / \mathrm{s}$, greater than $5.9 \mathrm{~m} / \mathrm{s}$.

The hourly precipitation data sets during 2007 to 2008 are divided by five classes, as follows: $0.0 \mathrm{~mm} / \mathrm{h}$, $0.1 \sim 2.4 \mathrm{~mm} / \mathrm{h}, 2.5 \sim 7.9 \mathrm{~mm} / \mathrm{h}, 8.0 \sim 15.9 \mathrm{~mm} / \mathrm{h}$, greater than $15.9 \mathrm{~mm} / \mathrm{h}$.

The annual on-site hourly average meteorological data sets at $10 \mathrm{~m}, 30 \mathrm{~m}, 70 \mathrm{~m}, 100 \mathrm{~m}$ levels are classified separately by six wind speed classes, six types of atmospheric stability, sixteen compass of wind direction and five type of precipitation classes to create a joint frequencies. A joint frequency at $70 \mathrm{~m}$ level which equals to the effluent release height is chosen for input meteorological data set of the model.

Two sets of dispersion parameters are input separately. One is obtained by series of 16 local scale atmospheric experiments in the site in 2007 illustrated by Figure 3. Another is suitable for large roughness terrain and recommended by IAEA $^{6}$, and these dispersion parameters at $100 \mathrm{~m}$ level are selected as the model dispersion parameters. Mixing layer height concurrently with atmospheric stability is used in Table 3. 
In the end, four nuclides include ${ }^{85} \mathrm{Kr},{ }^{137} \mathrm{Cs},{ }^{131} \mathrm{I},{ }^{135} \mathrm{Xe}$ are selected. Two sets of annual dispersion factors of 192 sectors of the site are evaluated by the straight-line model. One is calculated by on-site dispersion parameters. Another is calculated by IAEA $^{6}$ large roughness dispersion parameters.

\section{Lagrangian trajectory puff model}

Lagrangian trajectory puff model is developed for coping well with the in-stationary and inhomogeneous meteorological situations. The model either commonly applies to moderate topography on a horizontal scale of up to $80 \mathrm{~km}$, or responds to temporal and spatial meteorological conditions. It can simulate the time changing releases of airborne materials by sequentially releasing a series of Gaussian shaped puffs at a fixed rate on a specified grid. The amount of airborne materials allocated to individual puffs equals the release rate multiplies the time elapsed between puff releases.

It can be applied by using external generated wind fields from separate wind modules. The individual puffs are advected by the wind field $\bar{V}$ that is a specified function of co-ordinate $\bar{r}$, time $\mathrm{t}$ and averaging time $\mathrm{t}_{\mathrm{av}}$. The formula is:

$$
\bar{V}=\bar{V}\left(\bar{r}, t, t_{a v}\right)
$$

The Growth of the puffs is computed from atmospheric stability in the dispersion area. The height of the inversion cap and source height can easily be adjusted and a parameter controls the amount of reflection of pollutant at the surface of the ground and of the inversion cap. Dry deposition parameters are chosen for the individual puffs according to type of isotope, atmospheric stability and wind speed and surface roughness. Wet deposition is modeled similar to dry deposition only with the difference that the deposition velocity is replaced by a wash-out coefficient, the magnitude of which depends on the rain intensity.

Once the advection and size of all puffs have been calculated, updated grid concentrations $\mathrm{c}_{\mathrm{i}}(\mathrm{x}, \mathrm{y}, \mathrm{z})$ are obtained at each grid point $(x, y, z)$ summing up all the contributions from the puffs in the grid.

Assuming Gaussian distributions and total ground and inversion lid reflection, the formula for the concentration in a grid point $(x, y, z)$ from puff number (i) is as follows:

$$
\begin{aligned}
& \chi_{i}\left(x_{g}, y_{g}, z_{g}\right)=\frac{Q_{(i)}}{(2 \pi)^{3 / 2} \sigma_{x y}(i)^{2} \sigma_{z}(i)} \times e^{-\lambda i T} \times \exp \left[-\frac{\left(x-x_{c}(i)\right)^{2}}{2 \sigma_{x y}(i)^{2}}\right] \\
& \times \exp \left[-\frac{\left(y-y_{c}(i)\right)^{2}}{2 \sigma_{x y}(i)^{2}}\right] \times\left\{\begin{array}{l}
\exp \left[-\frac{\left(z-z_{c}(i)\right)^{2}}{2 \sigma_{z}(i)^{2}}\right]+\exp \left[-\frac{\left(z+z_{c}(i)\right)^{2}}{2 \sigma_{z}(i)^{2}}\right] \\
+\exp \left[-\frac{\left(2 z_{i n v}-z_{c}(i)\right)^{2}}{2 \sigma_{z}(i)^{2}}\right]
\end{array}\right\}
\end{aligned}
$$

where $Q(i)$ is puff inventory in puff number (i), $x_{c}(i), y_{c}(i)$, $z_{c}(i)$ are center co-ordinates of puff number (i), and $z_{\text {inv }}$ is height of the inversion lid, $\lambda_{\mathrm{i}}$ is decay constant for isotope
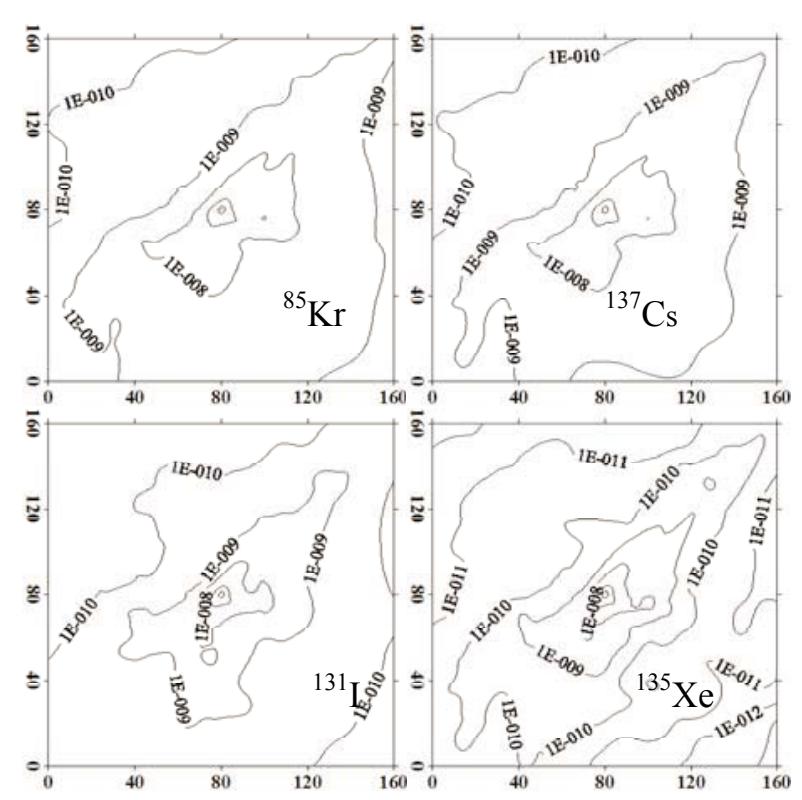

Fig. 4 The annual dispersion factors of ${ }^{85} \mathrm{Kr},{ }^{131} \mathrm{I},{ }^{137} \mathrm{Cs}$, and ${ }^{133} \mathrm{Xe}$ at each grid calculated by Lagrangian trajectory puff model, $160 \mathrm{~km} \times 160 \mathrm{~km}$

no. i, $\sigma_{x y}, \sigma_{z}$ is puff dispersion parameters in horizontal and vertical directions.

The model output consists of hourly average air concentration and deposition.

The set-up procedures are as follows:

The grid size is $161 \times 161$ grad units with $1 \mathrm{~km}$ mesh size. The position of source with $70 \mathrm{~m}$ elevated release is at the center of the calculation area with 8760 hours continuous even release rate and the same four nuclides are selected.

More than 8760 hourly wind fields consistent with above grid size at $70 \mathrm{~m}$ level were produced by the three dimensions objective diagnostic wind field model with the wind and temperature datum of one on-site and fifteen off-site meteorological stations beside elevations and roughness in the region of interest. More than 8760 hourly atmospheric stability and precipitation fields similar to wind fields were interpolated with its approximately dominating area. The atmospheric dispersion parameters and mixing height obtained by on-site experiments and measurements were used in the model. The model with above preprocessed input data could calculate 8760 hourly continuous even releases and produced 8760 hourly average concentration fields in time sequence for a full year.

8760 hourly average concentration fields at each grid are averaged in order to calculate annual dispersion concentration at each grid. The annual dispersion factors for each grid are the ratio of the annual dispersion concentration at each grid to the release rate. The annual dispersion factors for a given distance and direction same as the straight-line model can be obtained by inverse distance square interpolation method with the annual dispersion factors for each grid. Figure 4 illustrates the isolines of annual dispersion factors of ${ }^{85} \mathrm{Kr},{ }^{137} \mathrm{Cs},{ }^{131} \mathrm{I},{ }^{135} \mathrm{Xe}$ at each grid. 


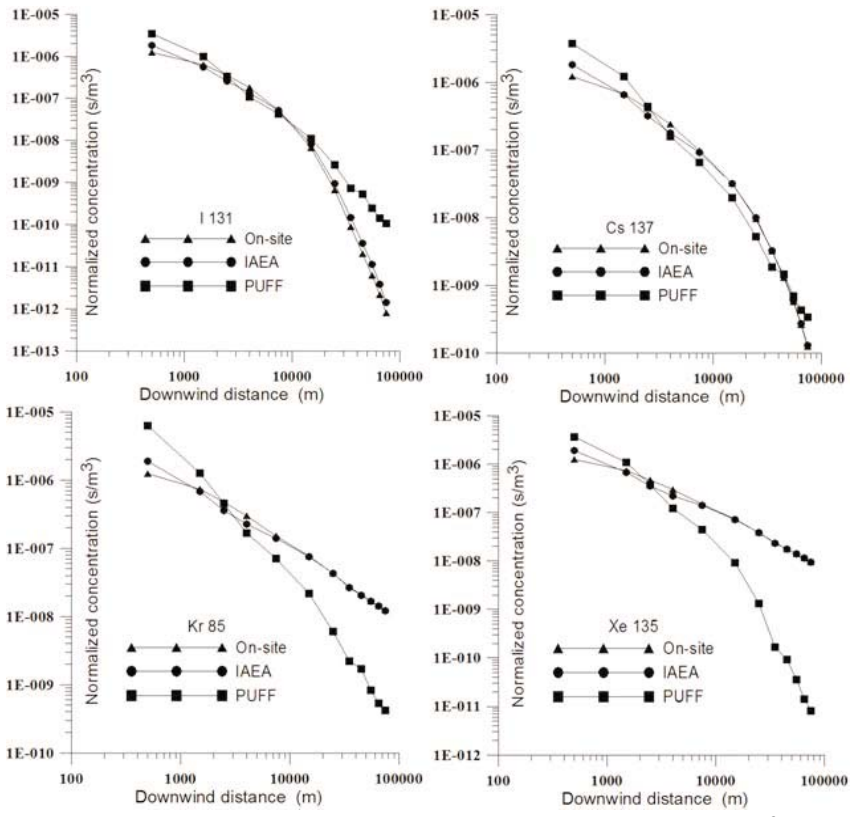

Fig. 5 Normalized concentrations for four nuclides include ${ }^{85} \mathrm{Kr}$, ${ }^{131} \mathrm{I},{ }^{137} \mathrm{Cs},{ }^{135} \mathrm{Xe}$ evaluated by the straight-line model separately with on-site, IAEA parameters and puff model at $12 \mathrm{NNE}$ compass sectors from $500 \mathrm{~m}$ to $100000 \mathrm{~m}$.

\section{Comparison and Analysis}

For the consideration of the topography and annual wind direction frequency, NNE compass sectors with more pronounced valley and more frequencies airflow has been selected, and three sets of dispersion factors for four nuclides include ${ }^{85} \mathrm{Kr},{ }^{137} \mathrm{Cs},{ }^{131} \mathrm{I},{ }^{135} \mathrm{Xe}$ were compared in these sectors. Figure 5 illustrates the results of comparison. It is obvious that the magnitude of dispersion factors evaluated by puff model less than $2 \mathrm{~km}$ downwind distance in the NNE compass direction is larger than the other two straight-line model results and the maximum ratio to straight-line model results can reach 2.4 3.6 near the distance from the release point. In the downwind distance far from the release point, the magnitude of dispersion factors evaluated by puff model is reduced so faster that for ${ }^{85} \mathrm{Kr},{ }^{137} \mathrm{Cs}$, ${ }^{135} \mathrm{Xe}$, nuclides dispersion factors evaluated by puff model are less than the other two. Only ${ }^{131}$ I normalized concentration evaluated by puff model in the downwind distance greater than $10 \mathrm{~km}$ is reduced slower than the other two because of the difference from the wet and dry deposition depletions effects of the two methods for ${ }^{131} \mathrm{I}$. However, the wet and dry deposition depletions effects are very tiny relative to the air concentration magnitude especially for the nearer downwind distance.

\section{Conclusions}

Two sets of results are evaluated by Gaussian straight-line models with recommended On-site and IAEA dispersion parameters as well as On-site meteorological station datum, and One set of result is evaluated by Lagrangian trajectory puff model with meteorological and topography datum in the region of the FuLing nuclear power plant site. These three sets of results are compared separately with four nuclides at 12 downwind distance of NNE compass direction. The comparison with the atmospheric dispersion factors calculated by the usual models shows that the annual atmospheric dispersion factors from hourly puff model simulations is about 2.6 3.4 times depending on different nuclide. So the airflow patterns and plume diffusions are mainly affected by the topography in the region of the site such as hills and river valleys. Especially higher calm and low wind speed frequencies caused the recirculation of airflow, directional biases during periods of prolonged atmospheric stagnation to bring significantly the higher normalized concentrations near the site. Therefore, it should be careful to apply the usual models to the site with complex environmental conditions like Fuling site, and also to analyze the conservative application of the models and parameters. Furthermore, more detailed evaluation and analysis is needed for accident atmospheric factors or short term dispersions over the complex terrain.

\section{Acknowledgment}

First I thanks for Professor YAO Rentai, under his guidance, we have developed this work, and he gave me a chance to complete the paper. This work has also benefited from the support of the Fuling nuclear power plant site applicant office. The On-site atmospheric dispersion experiments and meteorological observation are with the corporation of Chinese Academy of Meteorological Sciences. These researches are advised by Shanghai Nuclear Engineering Research and Design Institute.

\section{References}

1) IAEA, Atmospheric dispersion in relation to nuclear power plant sitting. A safety Guide No. 50-SG-S3, STI/PUB/549, 1980

2) U.S. Nuclear Regulatory Commission: Regulatory Guide 1.111, Revision 1. Methods for Estimating Atmospheric Transport and Dispersion of Gaseous Effluents in Routine Releases from Light-Water-Cooled Reactors. USNRC Office of Standards Development, Washington, D.C, 1977.

3) XOQDOQ : Computer Program for Meteorological Evaluation of Routine Effluent Releases at Nuclear Power Stations, Prepared by J.F.Sagendorf, J.T. Goll, W.F. Sandusky, Prepared for U.S. Nuclear Regulatory Commission. Published as NUREG-0324, 1982.9

4) PAVAN : An Atmospheric Dispersion Program for Evaluating Design Basis Accidental Releases of Radioactive Materials From Nuclear Stations, Prepared by T.J.Bander. Prepared for U.S. Nuclear Regulatory Commision. Published as NUREG/CR-2858, 1982.11

5) The Study for the atmospheric dispersion experiments in the region of nuclear power plant site, report, Prepared by China Institute for Radiation Protection, YAO Rentai, 2005-2008

6) IAEA, Generic models and parameters for assessing the environmental transfer of radio nuclides from routine release, Safety series No. 57, 1982 